ఠ

\title{
Role of carglumic acid in the treatment of acute hyperammonemia due to $\mathrm{N}$-acetylglutamate synthase deficiency
}

This article was published in the following Dove Press journal:

Therapeutics and Clinical Risk Management

| August 20| |

Number of times this article has been viewed

\section{Johannes Häberle}

Kinderspital Zürich, Abteilung Stoffwechsel, Zürich, Switzerland
Correspondence: Johannes Häberle Kinderspital Zürich, Abteilung Stoffwechsel, Steinwiesstrasse 75, $\mathrm{CH}-8032$ Zürich, Switzerland Tel +4I (0)44 2667342 Fax +4I (0)44 2667 7I 67 Email johannes.haeberle@kispi.uzh.ch
Abstract: N-acetylglutamate synthase (NAGS) deficiency is a rare inborn error of metabolism affecting ammonia detoxification in the urea cycle. The product of NAGS is $\mathrm{N}$-acetylglutamate which is the absolutely required allosteric activator of the first urea cycle enzyme carbamoylphosphate synthetase 1. In defects of NAGS, the urea cycle function can be severely affected resulting in fatal hyperammonemia in neonatal patients or at any later stage in life. NAGS deficiency can be treated with a structural analog of N-acetylglutamate, N-carbamyl-L-glutamate, which is available for enteral use as a licensed drug. Since NAGS deficiency is an extremely rare disorder, reports on the use of N-carbamyl-L-glutamate are mainly based on single patients. According to these, the drug is very effective in treating acute hyperammonemia by avoiding the need for detoxification during the acute metabolic decompensation. Also during long-term treatment, N-carbamyl-L-glutamate is effective in maintaining normal plasma ammonia levels and avoiding the need for additional drug therapy or protein-restricted diet. Open questions remain which concern the optimal dosage in acute and long-term use of N-carbamyl-L-glutamate and potential additional disorders in which the drug might also be effective in treating acute hyperammonemia. This review focuses on the role of N-carbamyl-L-glutamate for the treatment of acute hyperammonemia due to primary NAGS deficiency but will briefly discuss the current knowledge on the role of N-carbamyl-L-glutamate for treatment of secondary NAGS deficiencies.

Keywords: carglumic acid, carbamylglutamate, N-carbamyl-L-glutamate, N-acetylglutamate synthase deficiency, NAGS deficiency, hyperammonemia

\section{Introduction}

Deficiency of N-acetylglutamate synthase (NAGS deficiency; NAGSD; \#237310) belongs to the rare inborn errors of metabolism affecting the main pathway of ammonia detoxification, the urea cycle. The disorder leads to a deficiency of N-acetylglutamate (NAG), the product of NAGS (EC 2.3.1.1), which serves as the allosteric activator of the first enzyme of the urea cycle, carbamoylphosphate synthetase 1 (CPS1). ${ }^{1}$ NAGSD can lead to neonatal onset life-threatening hyperammonemia ${ }^{2,3}$ but patients with a late presentation are also reported. ${ }^{4-6}$ The first patient suffering from NAGSD was described in $1981^{2}$ and since then a small number of clinical reports have added further patients. ${ }^{4,5,7-16}$

Primary NAGSD is caused by mutations in $N A G S,{ }^{9}$ a gene located on $17 \mathrm{q} 21.31$ which was described some years ago. ${ }^{10,17,18}$

In addition, deficiency of NAGS can also be secondary to inhibition of the enzyme by toxic metabolites or caused by lack of substrates. Inhibition of NAGS is assumed 
to occur in some organic acidopathies ${ }^{19-23}$ or in valproateinduced hyperammonemia. ${ }^{24}$

As soon as the diagnosis is suspected, patients with primary NAGSD should be treated with carglumic acid (synonymous: carbamylglutamate, CG, N-carbamyl-Lglutamate; systematic name: (2S)-2-(carbamoylamino) pentanedioic acid), which has been a licensed drug in Europe since 2003 and in the US since 2010 (Carbaglu $^{\circledR}$, Orphan Europe, Paris, France). ${ }^{25-27}$ Most patients with primary NAGSD who take CG do not need additional drugs or protein restriction in their diet, unless during acute illness or metabolic decompensation.

Patients with secondary NAGSD can be affected by acute hyperammonemia to the same extent as in primary NAGSD and might therefore benefit from treatment with CG. However, hyperammonemia caused by defects outside the urea cycle is often multifactorial and only in part due to secondary NAGSD. Accordingly, use of CG for indications other than primary NAGSD needs several additional considerations and should be discussed separately.

This review will focus on the role of CG for the treatment of acute hyperammonemia due to primary NAGSD. In addition, the current knowledge on the role of $\mathrm{CG}$ for treatment of secondary NAGSD will be briefly presented and discussed.

\section{Pharmacology and properties of carbamylglutamate}

CG is a structural analog of human NAG (Figure 1) that can enter mitochondria to reach CPS1 which is only expressed intramitochondrially. Experiments in rats, both in vivo and in vitro, showed that CG activates the hepatic CPS1. ${ }^{25,28}$ This was concluded based on a decrease of ammonia and an increase of urea concentrations in the blood, respectively, as well as an increase in CPS1 activity in the liver. NAG or $\mathrm{CG}$ is absolutely required for the urea cycle function. However, while CG is very effective in activating CPS1, it

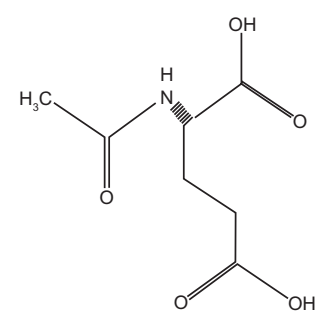

$\mathrm{N}$-acetylgutamate

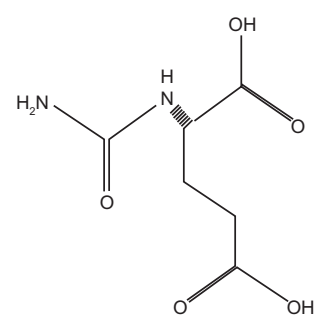

$\mathrm{N}$-carbamyl-L-glutamate
Figure I Chemical structures of $\mathrm{N}$-acetylglutamate and $\mathrm{N}$-carbamyl-L-glutamate. does not regulate the urea cycle function. In this respect, CG is different from NAG which can regulate the urea cycle and which varies in concentration depending on the protein content of the diet, as does the NAGS activity. ${ }^{3}$

CG has been known as a chemical agent and was used as an unlicensed drug for many years. After becoming a licensed drug, Carbaglu ${ }^{\circledR}$ is available as tablets for oral/ enteral use only. If dissolved in water, the solution has an acidic taste. While human NAG is degraded in the cytosol by amino acylase, CG is not subject to intracellular degradation.

The pharmacokinetic characteristics were investigated in 12 healthy male probands who each received $100 \mathrm{mg}$ CG per $\mathrm{kg}$ bodyweight ( $\mathrm{bw}$ ). The highest plasma concentrations of $2.6 \mu \mathrm{g} / \mathrm{mL}$ (mean, range 1.8-4.8) were observed at 3 hours (median, range 2-4) after intake with a half-life elimination time of 5.6 hours (mean, range 4.3-9.5). Rate of resorption was about $30 \%$ while $5 \%-9 \%$ of CG was unchanged excreted in urine. Within 12 hours after intake, about $70 \%$ of CG is lost through urine or feces but small amounts of CG can still be found after 96 hours.

\section{Indication, dosing, and contraindications}

Currently, Carbaglu ${ }^{\circledR}$ is registered for use in patients with primary NAGSD both as adjunctive therapy in acute hyperammonemia and during long-term treatment.

Carbaglu $^{\circledR}$ is available as $200 \mathrm{mg}$ tablets for enteral use only and should be administered after solution in water (minimum of 5-10 mL per $200 \mathrm{mg}$ tablet) either orally or through a nasogastric or gastrostomy tube.

Treatment with CG may be started already on the first day of life. The recommended daily initial dose is $100 \mathrm{mg} / \mathrm{kg}$ bw, and this can be increased to $250 \mathrm{mg} / \mathrm{kg}$ bw if necessary. The dose during long-term treatment should be adjusted to maintain normal ammonia levels for age. The long-term daily maintenance dose can be as low as $10-15 \mathrm{mg} / \mathrm{kg}$ bw. ${ }^{29-30}$ In patients $\geq 25 \mathrm{~kg}$ bw, the recommended daily dose is $2.2 \mathrm{~g} / \mathrm{m}^{2}$.

The daily dose should be divided in 3-4 doses based on $\mathrm{a} \mathrm{T}_{1 / 2}=5-6$ hours which is substantially longer than $T_{1 / 2}$ of the physiological analog NAG. The intake of CG is recommended immediately before a meal.

Contraindications refer to hypersensitivity to the active substance or to any of the excipients; in addition, use of CG is not recommended during pregnancy based on lack of human data and contraindicated during breast-feeding based on its presence in the milk of lactating rats. 


\section{Adverse events}

In the first NAGSD patient treated with CG, symptoms of intoxication occurred when the daily CG dose was gradually increased to $750 \mathrm{mg} / \mathrm{kg}$ bw. ${ }^{25}$ This so called "Chinese restaurant syndrome", characterized as a sympathomimetic reaction including tachycardia, profuse sweating, increased bronchial secretion and temperature, and persistent crying, ${ }^{25}$ was probably due to the large dose given and was never described in any other patient. CG seems to be extremely well tolerated since almost no side-effects are reported. During the post-marketing surveillance, some adverse events did occur which were mostly not related to use of CG. According to the retrospective case series experience of the manufacturer on 23 patients treated over up to 20 years only 2 CG-related adverse events, namely bitter taste and hyperhydrosis, occurred..$^{31}$

\section{Methods}

A literature search using MEDLINE ${ }^{\circledR}$ was performed using "n-acetylglutamate", "hyperammonemia", and "NAG synthase" as search terms. All papers were included that addressed the subject of this article including case reports and expert opinions.

\section{Results and discussion}

The MEDLINE ${ }^{\circledR}$ search identified a total of 50 articles from 1972 to 2011. Of these, 25 were included in the analysis and the rest excluded because of lack of applicability for the purpose of this review. In detail, 1 controlled experimental study, 1 case series, 1 expert opinion, 3 animal studies, and 19 case reports were evaluated. Unfortunately, no randomized studies have investigated the use of $C G$ which is probably due to the rarity of the disease.

Most papers identified are case reports. These date back to 1981 when CG was first administered to a human NAGSD patient. ${ }^{2,25}$ Since then, various case reports have been published demonstrating the efficacy of CG treatment for acute and chronic management of NAGSD but with variable morbidity and mortality mostly depending on the clinical course prior to CG administration. $4,5,7,8,10,11,14,15,26,27,32$ Most authors used a different protocol for initiation and maintenance of CG treatment resulting in varying doses applied. Doses for initiation of treatment during acute hyperammonemia ranged in most reports from 100 to $250 \mathrm{mg} / \mathrm{kg}$ bw per day divided in 4 doses. Maintenance daily doses ranged from 15 to $150 \mathrm{mg} / \mathrm{kg}$ bw in most reports. In almost all instances, CG was given at least 3 times a day in accordance with the pharmacological properties and the need to mimic the physiological situation of a constant NAG availability. When the acute hyperammonemic phase was under control, dose of CG was reduced to the least effective daily dose which was reported to be as low as $15 \mathrm{mg} / \mathrm{kg} \mathrm{bw.} .^{29,30}$

In addition to the majority of NAGSD patients who presented as neonates, some patients with late-onset are described, in whom CG was successfully used to achieve a stable metabolic situation. ${ }^{6,30,33}$ In another patient with late-onset NAGSD, CG improved ammonia control but did not allow normalization of protein intake. ${ }^{16}$ To evaluate the effect of CG on urea production, a late-onset patient and her mother were investigated by in vivo stable isotope studies. .,33 $^{4}$ These showed a markedly reduced urea production at baseline which was increased more than 10 -fold following treatment with CG. This effect was consistent with complete restoration of ureagenesis.

There are only 2 reports on the long-term outcome in patients with NAGSD. ${ }^{12,29}$ The first described a 9-year follow-up in a patient with moderate psychomotor retardation who was on a liberal diet prescription but eventually died from deep coma at the age of 9.5 years. ${ }^{12}$ The outcome was more favorable in another patient who was treated from 3 months after birth and who remained neurologically normal at the age of 13 years. ${ }^{29}$ Besides, long-term data are available from 23 patients with NAGSD who were under treatment with CG for 7 to 249 months. Patients were treated with a mean initial daily dose of CG of $172 \mathrm{mg} / \mathrm{kg}$ bw and with a mean daily maintenance dose of $31 \mathrm{mg} / \mathrm{kg}$ bw. In this cohort, plasma ammonia and glutamine normalized quickly after start of therapy and remained within normal limits during the maintenance therapy, respectively. The neurological and psychomotor outcome was good since no patient deteriorated compared with the status at baseline. ${ }^{31}$

Probably the most convincing data concerning the effect of CG were reported in controlled experimental studies addressing the rate of ureagenesis as measured by isotope investigations in humans. ${ }^{21,34}$ These studies demonstrated that CG markedly enhances the rate of urea production in control subjects $(\mathrm{n}=17)$, and normalized urea production in 2 patients with NAGSD and propionic acidemia, respectively. However, whether this increase in ureagenesis does result in decreased ammonia toxicity resulting in an improved patient outcome must be studied further. At least, the results from isotope studies are not influenced by the often unknown and unpredictable additional factors which were likely present during the use of CG in many of the above case reports.

Costs of treatment with CG have been the subject of debate since licensing as an orphan drug led to a marked 
increase of the price compared with the unlicensed product. There are concerns that patients risk being denied full treatment as a result of the high costs. ${ }^{35}$

\section{Animal studies}

Rats given a lethal dose of ammonium acetate could be rescued by CG alone in $61 \%$ of the animals and in $100 \%$ if $\mathrm{CG}$ was given in combination with L-arginine. ${ }^{28}$ Similarly, CG administered to Wistar rats and Swiss albino mice led to an increase of blood urea accompanied by a decrease in blood ammonia. ${ }^{36}$ These results suggested the use in patients with NAGSD and with partial CPS1 deficiency. In another study, Wistar rats fed a protein-free diet developed hyperammonemia which could be effectively treated with CG. ${ }^{37}$ This led to the suggestion that CG could be useful to restore NAG levels in more common disorders such as in liver cirrhosis.

\section{Further indications}

The use of CG has been suggested as a diagnostic tool in neonatal patients with hyperammonemia both for acute management and for identifying the underlying disorder. ${ }^{38}$ In a prospective study, 8 patients with a suspected urea cycle defect based on severe neonatal hyperammonemia and after exclusion of organic acidurias and fatty acid oxidation defects were subjected to oral CG treatment with a single initial dose of 114 to $200 \mathrm{mg} / \mathrm{kg} \mathrm{bw} .{ }^{38}$ In patients with later confirmed NAGSD, ammonia levels normalized within 8 hours. However, it is important to note that probably not all patients with NAGSD can be detected by a trial with CG during the acute hyperammonemic decompensation. One example was reported, when hyperammonemia did not resolve over 15 hours in a patient with severe neonatal onset of later confirmed NAGSD. ${ }^{15}$ Thus, use of CG must not delay initiation of other treatment modalities, such as intravenous sodium benzoate, sodium phenylacetate, and extracorporeal ammonia detoxification especially in cases in which the diagnosis is not yet established. Whether use of $\mathrm{CG}$ should be continued in case of initial unresponsiveness must be decided on an individual basis depending on all circumstances.

In addition to the use of CG in primary NAGSD, the use of $\mathrm{CG}$ for treatment of acute hyperammonemia was reported in a few other disorders and was also discussed based on isotope studies in healthy volunteers. ${ }^{34}$ Recently, the first prospective clinical trial in pediatric patients with propionic acidemia presented evidence of the benefit of $\mathrm{CG}$ on plasma ammonia and ureagenesis. ${ }^{39}$ Lately, the indications of Carbaglu ${ }^{\circledR}$ were extended to the use in hyperammonemia due to isovaleric acidemia, methymalonic acidemia, and propionic acidemia.

While the papers listed in Table 1 report on the successful use of CG, there might well be a bias due to under-reporting of ineffective interventions. For instance, the author of this review has given $\mathrm{CG}$ to a patient with isovaleric acidemia during severe neonatal decompensation but without any effect on ammonia levels. Moreover, it should be noted that most papers listed in Table 1 are single case reports and their findings should be further verified in controlled studies. Unlike with primary NAGSD, this research should be feasible in the group of organic acidemias given their higher prevalence. Obviously, the best way to achieve this would be in an international multi-center approach including centers from Europe and the US.

In a recent paper, the pathophysiology of valproateinduced hyperammonemia was investigated. ${ }^{24}$ It has long

Table I Disorders for which CG has been described

\begin{tabular}{lll}
\hline Disorders & Patients number; age & Outcome \\
\hline CPSI deficiency & I; 3 years & Normalization of plasma ammonia and glutamine \\
Hyperinsulinism/hyperammonemia syndrome & I; 5 years & Moderate decrease of plasma ammonia \\
Methylmalonic acidemia & I; neonatal & Enhanced lowering of plasma ammonia \\
Propionic acidemia & $2 ;$ neonatal & Enhanced lowering of plasma ammonia \\
Propionic acidemia & $2 ;$ neonatal & Dramatic fall in plasma ammonia with CG dose \\
& & 250 mg/kg; no response with CG dose 25 mg/kg \\
Propionic acidemia & I; 6 years & Increased urea production, but not normalized \\
Maple syrup urine disease & I; 4 years & Significant decrease of plasma ammonia \\
Propionic acidemia & $2 ;$ neonatal & Enhanced lowering of plasma ammonia \\
Propionic acidemia & $7 ;$ I5 months to I3 years & Decrease in plasma ammonia and glutamine \\
Methylmalonic acidemia, Propionic acidemia & Each I; neonatal & Rapid normalization of plasma ammonia \\
Propionic acidemia & $4 ;$ neonatal & Effective in controlling hyperammonemia but no \\
& & change of disease course; 3 of the 4 patients died
\end{tabular}

Abbreviations: CG, carglumic acid; CPSI, carbamoylphosphate synthetase I. 
been speculated that valproate leads to a direct inhibition of NAGS. In an elegant study, NAGS inhibition was demonstrated to be due to accumulation of valproyl-CoA, a valproate metabolite. According to this finding, use of $\mathrm{CG}$ in valproate-induced hyperammonemia has a rationale.

\section{Conclusion}

The role of CG in the treatment of acute hyperammonemia due to $\mathrm{N}$-acetylglutamate synthase deficiency is very clear and supported by evidence from scientific work, animal studies, and mostly clinical case reports. Open questions remain concerning the dose required during the initiation of therapy and during long-term therapy. Also, whether adjunctive drug therapy or protein-restricted diet is required needs to be defined in more detail, although it seems that CG can be the sole treatment for NAGSD. The role of CG for other disorders such as organic acidemias is less clear despite increasing evidence from case reports and isotope studies supporting the beneficial effect in acute hyperammonemia.

\section{Disclosure}

The author has been an invited speaker at scientific conferences organized by Orphan Europe and received travel support for this. Moreover, the author holds a contract with Orphan Europe for conducting molecular genetic investigations in patients with a suspicion of NAGS or CPS1 deficiencies.

\section{References}

1. Brusilow S, Horwich A. Urea cycle enzymes. In: Scriver C, Beaudet A, Sly W, Valle D, eds. The Metabolic and Molecular Bases of Inherited Disease. 8th ed. New York: McGraw-Hill; 2001:1909-1963.

2. Bachmann C, Krahenbuhl S, Colombo JP, Schubiger G, Jaggi KH, Tonz O. N-acetylglutamate synthetase deficiency: a disorder of ammonia detoxication. N Engl J Med. 1981;304(9):543.

3. Colombo JP. N-acetylglutamate synthetase (NAGS) deficiency. $A d v$ Exp Med Biol. 1994;368:135-143.

4. Caldovic L, Morizono H, Panglao MG, et al. Late onset N-acetylglutamate synthase deficiency caused by hypomorphic alleles. Hum Mutat. 2005; 25(3):293-298.

5. Elpeleg ON, Colombo JP, Amir N, Bachmann C, Hurvitz H. Late-onset form of partial $\mathrm{N}$-acetylglutamate synthetase deficiency. Eur J Pediatr. 1990;149(9):634-636

6. Plecko B, Erwa W, Wermuth B. Partial N-acetylglutamate synthetase deficiency in a 13-year-old girl: diagnosis and response to treatment with N-carbamylglutamate. Eur J Pediatr. 1998;157(12):996-998.

7. Burlina AB, Bachmann C, Wermuth B, et al. Partial N-acetylglutamate synthetase deficiency: a new case with uncontrollable movement disorders. J Inherit Metab Dis. 1992;15(3):395-398.

8. Caldovic L, Morizono H, Panglao MG, Cheng SF, Packman S, Tuchman M. Null mutations in the N-acetylglutamate synthase gene associated with acute neonatal disease and hyperammonemia. Hum Genet. 2003;112(4):364-368.

9. Caldovic L, Morizono H, Tuchman M. Mutations and polymorphisms in the human N-acetylglutamate synthase (NAGS) gene. Hum mutat. 2007;28(8):754-759.
10. Elpeleg O, Shaag A, Ben-Shalom E, Schmid T, Bachmann C. N-acetylglutamate synthase deficiency and the treatment of hyperammonemic encephalopathy. Ann Neurol. 2002;52(6):845-849.

11. Heckmann M, Wermuth B, Häberle J, Koch HG, Gortner L, Kreuder JG Misleading diagnosis of partial $\mathrm{N}$-acetylglutamate synthase deficiency based on enzyme measurement corrected by mutation analysis. Acta Paediatr. 2005;94(1):121-124.

12. Schubiger G, Bachmann C, Barben P, Colombo JP, Tonz O, Schupbach D. N-acetylglutamate synthetase deficiency: diagnosis, management and follow-up of a rare disorder of ammonia detoxication. Eur J Pediatr. 1991;150(5):353-356.

13. Häberle J, Denecke J, Schmidt E, Koch HG. Diagnosis of N-acetylglutamate synthase deficiency by use of cultured fibroblasts and avoidance of nonsense-mediated mRNA decay. J Inherit Metab Dis. 2003;26(6):601-605.

14. Häberle J, Koch HG. Genetic approach to prenatal diagnosis in urea cycle defects. Prenat Diagn. 2004;24(5):378-383.

15. Nordenstrom A, Halldin M, Hallberg B, Alm J. A trial with $\mathrm{N}$-carbamylglutamate may not detect all patients with NAGS deficiency and neonatal onset. $J$ Inherit Metab Dis. 2007;30(3):400.

16. Forget PP, van Oosterhout M, Bakker JA, Wermuth B, Vles JS, Spaapen LJ. Partial N-acetyl-glutamate synthetase deficiency masquerading as a valproic acid-induced Reye-like syndrome. Acta Paediatr. 1999;88(12):1409-1411.

17. Caldovic L, Morizono H, Gracia Panglao M, et al. Cloning and expression of the human $\mathrm{N}$-acetylglutamate synthase gene. Biochem Biophys Res Commun. 2002;299(4):581-586.

18. Häberle J, Schmidt E, Pauli S, et al. Mutation analysis in patients with N-acetylglutamate synthase deficiency. Hum Mutat. 2003;21(6): 593-597.

19. Jones S, Reed CA, Vijay S, Walter JH, Morris AA. N-Carbamylglutamate for neonatal hyperammonaemia in propionic acidaemia. $J$ Inherit Metab Dis. 2008.

20. Schwahn BC, Pieterse L, Bisset WM, Galloway PG, Robinson PH. Biochemical efficacy of N-carbamylglutamate in neonatal severe hyperammonaemia due to propionic acidaemia. Eur J Pediatr. 2010; 169(1):133-134.

21. Tuchman M, Caldovic L, Daikhin Y, et al. N-carbamylglutamate markedly enhances ureagenesis in $\mathrm{N}$-acetylglutamate deficiency and propionic acidemia as measured by isotopic incorporation and blood biomarkers. Pediatr Res. 2008;64(2):213-217.

22. Gebhardt B, Vlaho S, Fischer D, Sewell A, Bohles H. N-carbamylglutamate enhances ammonia detoxification in a patient with decompensated methylmalonic aciduria. Mol Genet Metab. 2003;79(4):303-304.

23. Kasapkara CS, Ezgu FS, Okur I, Tumer L, Biberoglu G, Hasanoglu A. $\mathrm{N}$-carbamylglutamate treatment for acute neonatal hyperammonemia in isovaleric acidemia. Eur J Pediatr. 2011;170(6):799-801.

24. Aires CC, van Cruchten A, Ijlst L, et al. New insights on the mechanisms of valproate-induced hyperammonemia: Inhibition of hepatic $\mathrm{N}$-acetylglutamate synthase activity by valproyl-CoA. J Hepatol. 2010.

25. Bachmann C, Colombo JP, Jaggi K. N-acetylglutamate synthetase (NAGS) deficiency: diagnosis, clinical observations and treatment Adv Exp Med Biol. 1982;153:39-45.

26. Guffon N, Vianey-Saban C, Bourgeois J, Rabier D, Colombo JP, Guibaud P. A new neonatal case of N-acetylglutamate synthase deficiency treated by carbamylglutamate. J Inherit Metab Dis. 1995;18(1):61-65.

27. Morris AA, Richmond SW, Oddie SJ, Pourfarzam M, Worthington V, Leonard JV. N-acetylglutamate synthetase deficiency: favourable experience with carbamylglutamate. J Inherit Metab Dis. 1998;21(8): 867-868.

28. Kim S, Paik WK, Cohen PP. Ammonia intoxication in rats: protection by N-carbamoyl-L-glutamate plus L-arginine. Proc Natl Acad Sci US A. 1972;69(12):3530-3533.

29. Gessler P, Buchal P, Schwenk HU, Wermuth B. Favourable long-term outcome after immediate treatment of neonatal hyperammonemia due to $\mathrm{N}$-acetylglutamate synthase deficiency. Eur J Pediatr. 2010; 169(2):197-199. 
30. Belanger-Quintana A, Martinez-Pardo M, Garcia MJ, et al. Hyperammonaemia as a cause of psychosis in an adolescent. Eur $J$ Pediatr. 2003;162(11):773-775.

31. Guffon N, Gessler P, Galloway P, et al. Treatment of NAGS deficiency: retrospective data on 23 patients treated with carglumic acid over 16 years [abstract]. Mol Genet Metab. 2011;102(3):286-287.

32. Hinnie J, Colombo JP, Wermuth B, Dryburgh FJ. N-Acetylglutamate synthetase deficiency responding to carbamylglutamate. J Inherit Metab Dis. 1997;20(6):839-840.

33. Caldovic L, Morizono H, Daikhin Y, et al. Restoration of ureagenesis in $\mathrm{N}$-acetylglutamate synthase deficiency by $\mathrm{N}$-carbamylglutamate. J Pediatr. 2004;145(4):552-554.

34. Ah Mew N, Payan I, Daikhin Y, Nissim I, Tuchman M, Yudkoff M. Effects of a single dose of N-carbamylglutamate on the rate of ureagenesis. Mol Genet Metab. 2009;98(4):325-330.

35. Leonard JV, Richmond S. Pricing of orphan drugs. Lancet. 2009; 373(9662):462.

36. O'Connor JE, Jorda A, Grisolia S. Acute and chronic effects of carbamyl glutamate on blood urea and ammonia. Eur J Pediatr. 1985;143(3):196-197.

37. Grau E, Felipo V, Minana MD, Grisolia S. Treatment of hyperammonemia with carbamylglutamate in rats. Hepatology (Baltimore, Md). 1992; 15(3):446-448.

38. Guffon N, Schiff M, Cheillan D, Wermuth B, Häberle J, Vianey-Saban C. Neonatal hyperammonemia: the N-carbamoyl-L-glutamic acid test. J Pediatr. 2005;147(2):260-262.
39. Ah Mew N, McCarter R, Daikhin Y, Nissim I, Yudkoff M, Tuchman M. N-carbamylglutamate augments ureagenesis and reduces ammonia and glutamine in propionic acidemia. Pediatrics. 2010;126(1): e208-e214.

40. Kuchler G, Rabier D, Poggi-Travert F, et al. Therapeutic use of carbamylglutamate in the case of carbamoyl-phosphate synthetase deficiency. J Inherit Metab Dis. 1996;19(2):220-222.

41. Huijmans JG, Duran M, de Klerk JB, Rovers MJ, Scholte HR. Functional hyperactivity of hepatic glutamate dehydrogenase as a cause of the hyperinsulinism/hyperammonemia syndrome: effect of treatment. Pediatrics. 2000;106(3):596-600.

42. Gebhardt B, Dittrich S, Parbel S, Vlaho S, Matsika O, Bohles H. $\mathrm{N}$-carbamylglutamate protects patients with decompensated propionic aciduria from hyperammonaemia. J Inherit Metab Dis. 2005;28(2): 241-244.

43. Kalkan Ucar S, Coker M, Habif S, et al. The first use of N-carbamylglutamate in a patient with decompensated maple syrup urine disease. Metab Brain Dis. 2009;24(3):409-414.

44. Filippi L, Gozzini E, Fiorini P, Malvagia S, la Marca G, Donati MA. $\mathrm{N}$-carbamylglutamate in emergency management of hyperammonemia in neonatal acute onset propionic and methylmalonic aciduria. Neonatology. 2010;97(3):286-290.

45. Lévesque S, Karalis A, Lambert M, Russell L. Outcome of propionic acidemia treated at presentation with N-carbamylglutamate (abstract). Mol Genet Metab. 2010;99:203.
Therapeutics and Clinical Risk Management

\section{Publish your work in this journal}

Therapeutics and Clinical Risk Management is an international, peerreviewed journal of clinical therapeutics and risk management, focusing on concise rapid reporting of clinical studies in all therapeutic areas, outcomes, safety, and programs for the effective, safe, and sustained use of medicines. This journal is indexed on PubMed Central, CAS,

\section{Dovepress}

EMBase, Scopus and the Elsevier Bibliographic databases. The manuscript management system is completely online and includes a very quick and fair peer-review system, which is all easy to use. Visit $\mathrm{http} / / / \mathrm{www}$.dovepress.com/testimonials.php to read real quotes from published authors. 